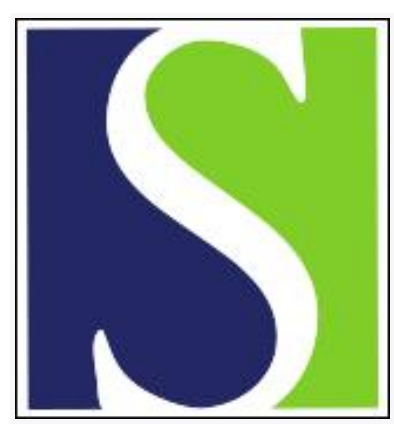

Scand J Work Environ Health 1995;21(6):494-503

https://doi.org/10.5271/sjweh.66

Issue date: Dec 1995

Cumulative injury rate and potential workdays and salary lost by Chang Y-C, Wang J-D

Key terms: frequency rate; human capital; occupational injury; proportion of potential workdays lost; severity index; severity rate; work capability

This article in PubMed: www.ncbi.nlm.nih.gov/pubmed/8824756

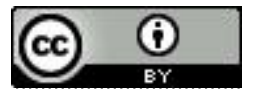




\title{
Cumulative injury rate and potential workdays and salary lost
}

\author{
by Yu-Chen Chang, MD, ${ }^{1,2}$ Jung-Der Wang, $M D^{1}$
}

\begin{abstract}
Chang Y-C, Wang J-D. Cumulative injury rate and potential workdays and salary lost. Scand J Work Environ Health 1995;21:494-503.

Objectives The purpose of this study was to examine alternative methods for quantifying occupational injuries and to estimate the costs of foregone earnings due to these injuries.

Methods A model based on the three possible outcomes of occupational injuries (premature death, permanent disability, and temporary dysfunction) was proposed, and several new indices were developed to measure the frequency and severity of occupational injuries. In the calculations, the human capital method was employed to measure potential salary lost due to occupational injury. An example was adopted from a steel corporation to demonstrate these indices.

Results The cumulative injury rates, based on age and duration of employment, represented the average cumulative risk of acquiring occupational injuries by lifetime work duration and by employment duration, respectively. The severity index revealed the rate of estimated potential workdays lost by incorporating both the age at which an injury occurred and the severity weighting factors of various disabilities into the formula. After the estimated potential workdays lost was divided by the total employees' potential affordable workdays, the proportion of potential workdays lost showed a result that adjusted for the varied age distribution in each year implicitly. The potential loss in salary calculated the foregone earnings of occupational injuries, which could be considered as a lower limit of the monetary cost estimated by the willingness-to-pay method.

Conclusions Such indices supplement disabling frequency and severity rates. They cannot only be applied to occupational safety monitoring, but also to the policy-making process in occupational safety and health.
\end{abstract}

Key terms human capital, frequency rate, occupational injury, proportion of potential workdays lost, severity index, severity rate, work capability.

Maximizing expected value is the primary goal of a firm; this statement constitutes the conceptual basis of the firm theory of economics (1). From an economic point of view, employees are the most important keys to the quality of products, services, or goods. To be competitive in the marketplace, most firms try to increase their productivity, which is sometimes promoted at the sacrifice of occupational safety and health. However, accidental occupational injuries may not only damage a company's public image, but also impede productivity by damaging the employee's health and resulting in temporary or permanent physical and mental impairment, or even premature death. To an employee, an occupational injury not only brings economic loss, suffering, grief, physical and mental impairment or even death, but it also burdens the family as well. The reduction in productivity and the increase in expended resources usually produce a substantial and countless cost to society, including both economic and noneconomic costs $(2,3)$.
Therefore, the efficient prevention of occupational injuries is an earnest and challenging task to be met by both firms and governments. The current statistical tools used for occupational injuries, such as disabling frequency and severity rates, have been used for more than two decades (4). Although these two measurements have been used extensively throughout the world, they are not without limitations. In this article, we first review these measurements and then propose alternative or supplemental methods for quantifying occupational injuries and their potential impacts.

\section{Disabling frequency and severity rates}

Disabling frequency and severity rates are the two most widely used indices used to evaluate occupational injuries. The frequency rate quantifies the number of occu-

1 Center for Research of Environmental and Occupational Diseases, Institute of Occupational Medicine and Industrial Hygiene, National Taiwan University College of Public Health, Taipei, Taiwan.

2 Department of Family Medicine, Tainan Municipal Hospital, Tainan, Taiwan.

Reprint requests to: Dr Jung-Der Wang, Center for Research of Environmental and Occupational Diseases, Institute of Occupational Medicine and Industrial Hygiene, National Taiwan University College of Public Health, No 1, Section 1, Jen-Ai Road, Taipei, Taiwan, ROC 10016. 
pational injuries in a firm per million person-hours worked yearly. The severity rate measures the total number of disabled days of a firm per million personhours worked yearly. These two indices were adopted by the American National Standards Institute (ANSI) in 1967 (5). Disabling injuries are usually classified into the following four categories: (i) deaths, (ii) permanent total disabilities, (iii) permanent partial disabilities, and (iv) temporary disabilities. An injury resulting in permanent disability is coded as a specific number of "disabled days" that is retrieved from ANSI's standard scale of time charges of different injuries (5). For example, death and permanent total disability are charged with the highest number of workdays lost (6000 days), and a permanent partial disability is charged with the number of days less than 6000 based on its severity. If an injury involves multiple parts of the body, the total number of days is usually charged with the sum of the parts with a ceiling limit of 6000 days. The formulas to compute the frequency and severity rates within a specified period of time (eg, a year) are as follows: disabling frequency rate $=($ total number of disabling injuries $\times 1000000) /($ total number of person-hours worked in a firm); disabling severity rate $=($ total number of disabled days $x$ 1000000 ) / (total number of person-hours worked in a firm).

In general, these two indices describe the occupational injuries of a firm in two aspects, frequency and severity, and they seem sufficient to meet the needs of measurement. However, they have some inherent defects in measuring the occupational injuries of a firm. The disabling frequency rate does not take an employee's age into account nor does it adjust for the duration of employment. This statistic can hardly be interpreted as personal lifetime risk. Moreover, it is not usually suitable to compare between years or firms directly without rate standardization. While the disabling severity rate intends to reveal the magnitude of impact that injuries have upon a firm, the total number of disabled days (coded for deaths, permanent total and partial disabilities) are inflexible and fixed figures. On the surface, it seems to weight everybody equally; in reality, such an arbitrary coding schedule ignores the individual differences in the age at which an injury occurred and the contribution of the remaining work capability. The implication of disabled days calculated in this manner probably loses efficiency in human resource costing and accounting (6).

\section{Workyears of potential life lost}

The concept of years of potential life lost was developed as early as the 1940s, estimating the average potential years that a person could lose if a fatality occurred before the life expectancy of his or her age (7). It can be used to quantify the impact on society due to certain diseases or health-related events with the common unit "personyear." Although this concept cannot replace mortality rate, it can provide another aspect of the quantification of social impact by measuring the potential years lost due to certain etiology.

After years of potential life lost many other indices were developed to describe social impact by distinct conceptual definitions and calculating methods. Among these indicators, the workyears of potential life lost (WYPLL) involved estimating the average work years a person could lose if he or she died prematurely before his or her retirement age (7). WYPLL is usually defined as:

$$
\text { WYPLL }=\sum_{i=0}^{W-1} d i(N-W)+\sum_{i=W}^{N} d i(N-i)
$$

where $i=$ age at death, $d i=$ number of deaths at age $i$, $W=20$ years of age (lower cutoff value), $N=64$ years of age (upper cutoff value).

The worklife period is usually defined to be between 20 and 64 years of age. The formula contains two parts, including contributions from employees who died before 20 years of age and those who died between 20 and 64 years of age. Therefore, the workyears lost are 45 years and $64-i$ years, respectively. For people older than the usual retirement age (ie, 65 years), it is usually assumed that they have no workyears lost due to an injury. Although the workyears of potential life lost takes the age factor into account, it can only be applied to estimate the workyears lost due to death. Furthermore, with the competing general mortality being considered (8), the results of the workyears of potential life lost would be less than the figures derived from the preceding calculation. In addition to the case fatalities, there is still a need to assess the worklife lost due to permanent and temporary disabilities and to quantify the status of occupational injuries more reasonably.

\section{Cumulative injury rate of occupational injuries}

To tackle these problems, we propose alternative measurements to quantify the frequency and severity of occupational injuries. The cumulative injury rate integrates the age factor into the incidence rate itself. While incorporating the age distribution, it remains exactly the same as the cumulative incidence rate in common epidemiologic measurements with a specific definition of the incident of injury. It takes the following equation (9-11):

$$
\mathrm{CIR}_{20-64}=1-\mathrm{e}^{-\Sigma(\mathrm{R}) \mathrm{R}) \mathrm{i} \times \Delta \mathrm{ti}},
$$

where $\mathrm{CIR}_{20-64}=$ cumulative injury rate between 20 and 64 years of age (or any specified age period), $i=$ age 
stratum (eg, every 5 years of age as a stratum), IR = injury rate for a specific stratum, $\Delta t=$ the number of years in each age stratum (eg, if each age stratum is 5 years of age, then the $\Delta t=5$ ).

Applying the $\mathrm{CIR}_{20-64}$ to quantify the annual frequency of occupational injures in a firm takes advantage of the standardized age distribution and stands for estimating the average risk of acquiring occupational injuries through an employee's lifetime workyears in the firm. Simultaneously, the $\mathrm{CIR}_{20-64}$ can be interpreted as the annual risk indicator of the work environment of the firm. If the duration of employment is the major determinant to the occurrence of occupational injuries, rather than age, we can also quantify the CIR by specifying and dividing the stratum by the duration of employment instead of age. It has a similar equation to that of $\mathrm{CIR}_{20-64}$ :

$$
\mathrm{CIR}_{\text {DOE0-24 }}=1-\mathrm{e}^{-\Sigma(\mathrm{IR}) \mathrm{i} \times \Delta \mathrm{ti}} \text {, }
$$

where $\mathrm{CIR}_{\mathrm{DOE} 0-24}=$ cumulative injury rate on duration of employment between 0 and 24 years of employment (or any other specified duration), $i=$ stratum of duration of employment (eg, every 5 years as a stratum), $\Delta t=$ the

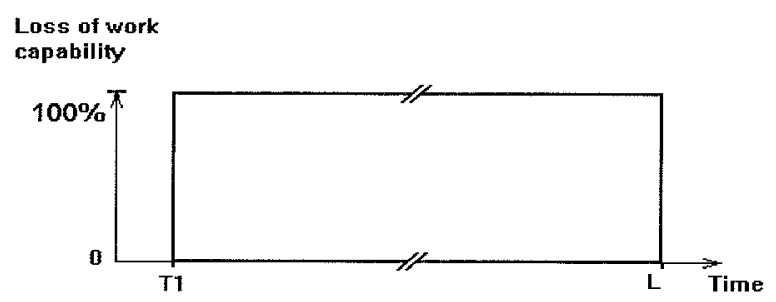

Figure 1. Potential workdays lost due to premature death from the occupational injury of an employee. (T1 denotes the age of onset, L represents the age of retirement)

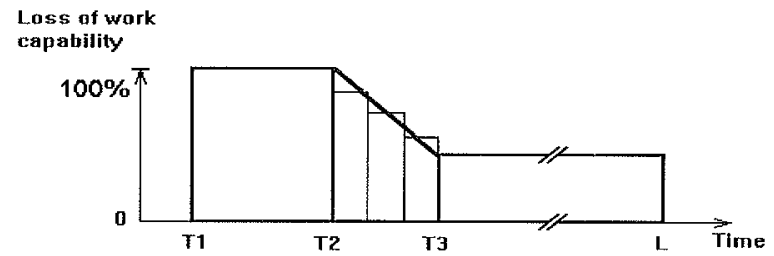

Figure 2. Potential workdays lost due to permanent disability from the occupational injury of an employee. (T2 indicates that the employee starts to come back to work with residual work capability and simultaneously under further rehabilitation; T3 means the time when the disability of the employee is stabilized and cannot be improved further)

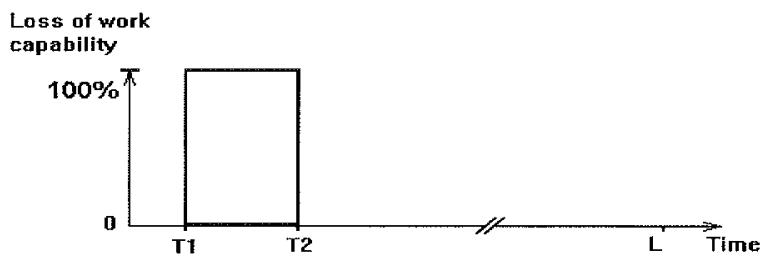

Figure 3. Potential workdays lost due to temporary dysfunction from the occupational injury of an employee. (T2 denotes the age of recovery) number of years in each stratum (eg, if each stratum is 5 years of employment, then the $\Delta t=5$ ).

\section{Potential workdays lost from occupational injuries}

The conceptual modification for the severity rate is to divide the outcomes of occupational injuries into the following main categories: (i) premature deaths (workers die immediately when an occupational injury occurs or die later but lose their work capability immediately after the occurrence of the injury) (figure 1); (ii) permanent disability (workers permanently lose various proportions of their work capability due to different injuries to their own bodies) (figure 2); (iii) temporary dysfunction: neither death nor permanent disability occurs due to the injury, but workers have to leave scheduled work for a certain number of days; when such a worker returns to work, he or she can work with the same capacity as before the injury (figure 3 ).

The following equations quantify the potential workdays lost corresponding to figures $1-3$ :

$$
\begin{aligned}
X 1= & \sum_{j=1}^{C F}(L-T 1)_{j} \times W t, \\
X 2= & \sum_{j=1}^{P D}\{(T 2-T 1) \times W t+(T 3-T 2) \times W m \\
& +(L-T 3) \times W s\}_{j}, \\
X 3= & \sum_{j=1}^{T D}(T 2-T 1)_{j} \times W t,
\end{aligned}
$$

(total potential workdays lost in the firm $=X 1+X 2+$ $X 3$ ), where $X 1=$ potential workdays lost from the cases of fatality, $X 2$ = potential workdays lost from the cases of permanent disability, $X 3=$ potential workdays lost from the cases of temporary dysfunction, $L=$ age of retirement, 65 years of age in this model, $C F=$ total number of fatalities, $P D=$ total number of permanent disabilities, $T D=$ total number of temporary dysfunctions, $W t=$ full loss of one's work capability, 1.0 in this model, $W m=$ mean work capability lost during $T 2$ to $T 3$, between 0 and $1, W_{S}=$ work capability lost compared with that before the injury and when the worker reaches a stable disability period at $T 3$, between 0 and 1 (usually $W m \geq W s)$.

Figure 1 indicates that when a deadly injury occurs at $T 1$, the injured employee loses his work capability immediately and permanently. The area from $T 1$ to $L$ denotes the potential workdays lost of this employee. In figure 2 , when permanent disability occurs at $T 1$, the injured employee loses work capability immediately, and the clinical courses of such a disability may vary individually (eg, visiting the emergency room, ward admissions, operations, rehabilitation or resting at home) depending on the severity and treatment of the injury. The area between $T 1$ and $T 2$ denotes the potential workdays 
lost from the beginning of the injury to the first day back to work. $T 2$ to $T 3$ represents the time after the injured employee returns to work, perhaps not yet fully recovered, and work capability improves as time passes. Finally, the injured employee reaches the point of stabilized disability (T3). If the worker's work capability gradually improves, then we can assume that the recovery is linear and $W m=(1+W s) / 2$. The period from $T 3$ to $L$ describes the expected duration in which the employee can contribute his work capability until the age of retirement, although his or her work capability might be only a proportion of that before the injury. The total area under the curve from $T 1$ to $L$ represents this employee's potential workdays lost if permanent disability occurs. Figure 3 shows that, when the temporary dysfunction occurs at $T 1$, the injured employee has to leave scheduled work immediately, but he or she can work with at least full work capability when he or she returns after a period away from work. The area enclosed represents the workdays lost due to the employee's injury.

The total potential workdays lost due to different outcomes in a firm within a certain period of time can be quantified by such approaches. In the situation of permanent disabilities, further investigation of the varied percentage of work capability lost after injury needs to be addressed to complete the whole model. Nevertheless, before such a survey has been undertaken and data obtained, we suggest temporarily adopting the values from the disability classification system for the worker's wage compensation. For example, in the system of disability classification used by the Bureau of Labor Insurance for the Taiwan-Fukien Area (12), there are 15 grades of wage compensation based on the severity of occupational injuries. The first grade, the most serious permanent disability, which is designated to receive 1800 days of wage compensation, is used as a base to derive the other varied percentage of work capability lost (table 1). In this situation, the work capability from $T 2$ to $T 3$ weighted by $W m$ would simply be substituted by the remaining work capability from $T 3$ through retirement (ie, Ws). Similarly, we can immediately obtain an assumed percentage of work capability lost by simply dividing the number of workdays lost charged to a specific injury by that of permanent total disability (ie, 6000 workdays) in ANSI's schedule (5), as in table 2.

With the total potential workdays lost as the numerator, we can then derive two indicators to quantify the severity of occupational injuries by introducing two ways of counting as denominators. The first indicator can be obtained by simply applying the new quantification of total potential workdays lost to the numerator of the disabling severity rate while retaining the same denominator. The quotient derived is an estimation of the severity of the impact of occupational injuries. To differentiate this value from the disabling severity rate itself, we have named it the severity index [severity index $=$ (total number of potential workdays lost $\times 1000000 /$ (total number of person-hours worked in a firm)].

Because the numerator of the severity index depends on the age of the injured workers, we can make a similar adjustment for the denominator to reduce such a bias. The second indicator is to calculate the total potential affordable workdays that could possibly be contributed by all employees before their retirement in the firm yearly and replace it as the denominator. Because the units of both the numerator and the denominator are potential workdays, the quotient is actually a proportion named the proportion of potential workdays lost (PPWDL). [PPWDL $=$ total number of potential workdays lost/ (total number of potential affordable workdays of all employees in a firm)].

Table 1. Assumed work capability lost after permanent disability granted according to the workmen's compensation schedule of Taiwan.

\begin{tabular}{lcc}
\hline $\begin{array}{l}\text { Grade of } \\
\text { permanent } \\
\text { disability }\end{array}$ & $\begin{array}{c}\text { Wage } \\
\text { compensation } \\
\text { in days }\end{array}$ & $\begin{array}{c}\text { Percentage of } \\
\text { work capability } \\
\text { lost }\end{array}$ \\
\hline 1 & 1800 & 100.0 \\
2 & 1500 & 83.3 \\
3 & 1260 & 70.0 \\
4 & 1110 & 61.7 \\
5 & 960 & 53.3 \\
6 & 810 & 45.0 \\
7 & 660 & 36.7 \\
8 & 540 & 30.0 \\
9 & 420 & 23.3 \\
10 & 330 & 18.3 \\
11 & 240 & 13.3 \\
12 & 150 & 8.3 \\
13 & 90 & 5.0 \\
14 & 60 & 3.3 \\
15 & 45 & 2.5 \\
\hline
\end{tabular}

Table 2. Examples of assumed percentage of work capability lost calculated from the tabulation of scheduled charges of permanent disabilities adopted by the American National Standards Institute (ANSI).

\begin{tabular}{lcc}
\hline Type of disability & $\begin{array}{c}\text { Disabled } \\
\text { days } \\
\text { charged }\end{array}$ & $\begin{array}{c}\text { Work } \\
\text { capability } \\
\text { lost (\%) }\end{array}$ \\
\hline Loss of member (amputation) & & \\
Distal phalange of great toe & 150 & 2.5 \\
Distal phalange of thumb & 300 & 5.0 \\
. &. &. \\
. &. &. \\
Foot at ankle & 2400 & 40.0 \\
Hand at wrist & 3000 & 50.0 \\
Any point above ankle and at or below knee & 3000 & 50.0 \\
Any point above wrist and at or below elbow & 3600 & 60.0 \\
Any point above knee & 4500 & 75.0 \\
Any point above elbow & 4500 & 75.0 \\
Impairment of function & & \\
One ear & 600 & 10.0 \\
One eye & 1800 & 30.0 \\
Both ears & 3000 & 50.0 \\
Both eyes & 6000 & 100.0 \\
\hline
\end{tabular}




\section{Potential salary lost due to occupational injuries}

In addition to the preceding indices, we have also formulated the estimation of potential salary lost, or foregone earnings, based on the same concept of potential workdays lost. It offers a way to estimate the social cost due to occupational injuries in monetary value. From an economic point of view, such figures are practical supplements which can be directly used to count the human capital cost of occupational injuries, and they are usually considered as the lower bound of the costs estimated from the willingness-to-pay method (13). Likewise, the development of the total potential salary lost can be built on the structure of the three outcomes of occupational injuries. We can adjust the incremental rate of labor productivity of an employee and discount future monetary value to present value in order to estimate both cases of premature death and permanent disability more accurately. The incremental rate of labor productivity can be substituted by the mean value of the incremental rate of GNP (gross national product) (eg, the average incremental rate of the GNP of Taiwan between 1981 and 1990 is $6.6 \%$ ). The discount rate usually fluctuates from year to year, and therefore a sensitivity analysis is needed to obtain a more reasonable range of estimation. As for cases of temporary disability, we simply sum up the actual loss in the year in which the injuries occurred. Because the potential workdays lost in cases of temporary dysfunction rarely encompass more than one year's time, the estimation of salary lost does not need the preceding adjustments. The equations for the estimation of the three different outcomes of occupational injuries are as follows:

1. The potential salary lost resulting from case fatality due to occupational injuries:

$$
M 1=\sum_{j}^{C F}\left\{M O D\left(x 1_{j} / 300\right) \times\left(P_{j / 300}\right)+\sum_{i=n+I}^{64} P_{j} \times\left(\frac{1+g}{1+r}\right)^{64-1}\right\},
$$

where $M 1=$ potential salary lost due to fatality, $x 1=$ individual potential workdays lost due to fatality, $M O D()$ $=$ remainder function of the arithmetic, $300=$ average number of total workdays in a year in Taiwan, $j=j$ th case of fatality, $n=$ age of years of the $j$ th case when the deadly injury occurred, $P j=$ annual income of the $j$ th case, $g=$ annual incremental rate of labor productivity, and $r=$ annual discount rate.

2. The potential salary lost resulting from permanent disability due to occupational injuries:

$$
\begin{aligned}
M 2= & \sum_{j}^{P D}\left\{M O D\left(x 2_{j} / 300\right) \times\left(P_{j / 300}\right)+\sum_{i=n+1}^{m} P_{j} \times\left(\frac{1+g}{1+r}\right)^{m-i}\right. \\
& \left.+\sum_{i=m+l}^{64} P_{j} \times W s \times\left(\frac{1+g}{1+r}\right)^{64-i}\right\}
\end{aligned}
$$

where $M 2=$ potential salary lost due to permanent disability, $j=j$ th case of permanent disability, $x 2=$ individual potential workdays lost due to permanent disability, $n=$ age in years of $j$ th case when the injury occurs, $m=$ age in years of $j$ th case when the worker comes back to work.

3. The salary lost resulting from temporary dysfunction due to occupational injuries:

$$
M 3=\sum_{j}^{T D} x_{3 j} \times\left(P_{j / 300}\right)
$$

where $M 3=$ salary lost from the cases of temporary dysfunction, $x 3$ = individual workdays lost due to temporary dysfunction (potential salary lost of all occupational injuries in the firm $=M 1+M 2+M 3$ ).

In the preceding equations, the income of each workday is assumed to be the annual income divided by 300 workdays, which is the average number of total workdays in a year in Taiwan. However, since the average total number of workdays of a worker in a year can vary from country to country or across different companies, we suggest using 300 workdays for the convenience of comparison.

\section{Example from a steel manufacturer}

To demonstrate the performance of these indices, we have applied them to the register data of occupational injuries of a steel company in Taiwan from 1985 through 1991. This company has a comprehensive registration system for all occupational injuries involving the loss of workdays. Table 3 lists the frequencies of various severities of disabling occupational injuries and the workdays lost estimated by various methods. There were $625 \mathrm{occu}-$ pational injuries during these years. Among them, 576 cases involved temporary dysfunction, 38 cases resulted in permanent disability, and 11 cases resulted in fatality. On the average, 20 workdays were lost per case of temporary dysfunction. In permanent disability, the potential workdays lost estimated from the work capability lost adopted from ANSI and Taiwan reveal that the numbers calculated from ANSI (table 2) are usually smaller than those from Taiwan (table 1), but both values are much greater than those of the total number of disabled days. A similar situation occurs in the case of fatality. It indicates that ANSI's original schedule may underestimate the impact of injury on production if workers are generally young. Although the frequencies of disabling injuries were high during 1987-1989, the numbers of permanent disabilities decreased, except in 1989. There were five cases of mortality in 1987 , and this value was the highest during these years. Table 4 summarizes the 
Table 3. Frequencies of various kinds of occupational injuries and respective estimation of workdays lost from a steel making company for different fiscal years. (PWDL = potential workdays lost, ANSI = American National Standards Institute)

\begin{tabular}{|c|c|c|c|c|c|c|c|c|}
\hline & \multicolumn{8}{|c|}{ Years } \\
\hline & 1985 & 1986 & 1987 & 1988 & 1989 & 1990 & 1991 & $1985-1991$ \\
\hline Number of injuries & 72 & 81 & 102 & 109 & 114 & 80 & 67 & 625 \\
\hline \multicolumn{9}{|l|}{ Temporary disability } \\
\hline $\begin{array}{l}\text { Number of cases } \\
\text { Disabled days }\end{array}$ & 60 & 74 & 92 & 103 & 106 & 77 & 64 & 576 \\
\hline $\begin{array}{l}\text { Total } \\
\text { Mean } \\
\text { SD }\end{array}$ & $\begin{array}{l}1301 \\
21.3 \\
22.4\end{array}$ & $\begin{array}{l}2189 \\
29.6 \\
54.1\end{array}$ & $\begin{array}{r}2472 \\
26.9 \\
44.7\end{array}$ & $\begin{array}{r}2091 \\
20.3 \\
33.5\end{array}$ & $\begin{array}{r}2389 \\
22.5 \\
32.0\end{array}$ & $\begin{array}{l}1558 \\
20.2 \\
31.9\end{array}$ & $\begin{array}{r}1991 \\
31.1 \\
58.2\end{array}$ & $\begin{array}{r}13991 \\
24.2 \\
40.6\end{array}$ \\
\hline \multicolumn{9}{|l|}{$P W D L^{b}$} \\
\hline $\begin{array}{l}\text { Total } \\
\text { Mean } \\
\text { SD }\end{array}$ & $\begin{array}{l}1069 \\
17.52 \\
18.39\end{array}$ & $\begin{array}{l}1798 \\
24.30 \\
44.44\end{array}$ & $\begin{array}{l}2030 \\
22.07 \\
36.71\end{array}$ & $\begin{array}{l}1717 \\
16.67 \\
27.48\end{array}$ & $\begin{array}{l}1962 \\
18.51 \\
26.26\end{array}$ & $\begin{array}{l}1280 \\
16.62 \\
26.18\end{array}$ & $\begin{array}{r}1635 \\
25.55 \\
47.83\end{array}$ & $\begin{array}{r}11492 \\
19.92 \\
33.31\end{array}$ \\
\hline \multicolumn{9}{|l|}{ Permanent disability } \\
\hline $\begin{array}{l}\text { Number of cases } \\
\text { Grade }\end{array}$ & 11 & 7 & 5 & 5 & 7 & 1 & 2 & 38 \\
\hline $\begin{array}{l}1-3 \\
4-6 \\
7-9 \\
10-12 \\
13-15\end{array}$ & $\begin{array}{l}\overline{1} \\
3 \\
4 \\
3\end{array}$ & $\begin{array}{c}- \\
2 \\
2 \\
3\end{array}$ & $\begin{array}{l}- \\
2 \\
3 \\
-\end{array}$ & $\begin{array}{l}\overline{-} \\
\frac{-}{5}\end{array}$ & $\begin{array}{l}\overline{1} \\
\frac{1}{5}\end{array}$ & $\begin{array}{l}\overline{-} \\
\overline{1} \\
\frac{1}{1}\end{array}$ & $\frac{\bar{z}}{\overline{1}}$ & $\begin{array}{r}- \\
2 \\
8 \\
10 \\
18\end{array}$ \\
\hline $\begin{array}{l}\text { Total disabled days } \\
\text { PWDL (ANSI) } \\
\text { PWDL (Taiwan) }\end{array}$ & $\begin{array}{r}8200 \\
15482 \\
19934\end{array}$ & $\begin{array}{r}3772 \\
8474 \\
12035\end{array}$ & $\begin{array}{l}4279 \\
7283 \\
8933\end{array}$ & $\begin{array}{r}793 \\
1737 \\
2434\end{array}$ & $\begin{array}{l}5935 \\
9544 \\
9740\end{array}$ & $\begin{array}{r}50 \\
122 \\
302\end{array}$ & $\begin{array}{r}235 \\
460 \\
1145\end{array}$ & $\begin{array}{l}23264 \\
43101 \\
54525\end{array}$ \\
\hline \multicolumn{9}{|l|}{ Occupational deaths } \\
\hline $\begin{array}{l}\text { Number of cases } \\
\text { Age group (years) }\end{array}$ & 1 & - & 5 & 1 & 1 & 2 & 1 & 11 \\
\hline $\begin{array}{l}<35 \\
35-49 \\
50-64\end{array}$ & $\frac{1}{-}$ & E & $\underline{5}$ & - & $\overline{1}$ & $\overline{2}$ & $\frac{1}{-}$ & $\begin{array}{r}8 \\
3 \\
- \\
\end{array}$ \\
\hline $\begin{array}{l}\text { Total number of disabled days }{ }^{\mathrm{a}} \\
\text { PWDL }\end{array}$ & $\begin{array}{r}6000 \\
10241\end{array}$ & - & $\begin{array}{l}30000 \\
51019\end{array}$ & $\begin{array}{r}6000 \\
10982\end{array}$ & $\begin{array}{l}6000 \\
4629\end{array}$ & $\begin{array}{l}12000 \\
12747\end{array}$ & $\begin{array}{r}6000 \\
10586\end{array}$ & $\begin{array}{r}66000 \\
100203\end{array}$ \\
\hline
\end{tabular}

a Total disabled days charged by the method of ANSI Z16.1-1967(5).

- Potential workdays lost is the same from either the ANSI or Taiwan method of estimation. The counting of total disabled days from temporary dysfunction usually included the holidays and weekends, which are not included in the PWDL.

- Potential workdays lost from the estimation of table 2.

d Potential workdays lost from the estimation of table 1.

Table 4. Number of employees, mean age, person-hours worked, potential affordable workdays, and various estimations of workdays lost from occupational injuries in a steel making company from different fiscal years.

\begin{tabular}{|c|c|c|c|c|c|c|c|}
\hline \multirow[t]{2}{*}{ Years } & \multirow{2}{*}{$\begin{array}{l}\text { Number } \\
\text { of } \\
\text { employees }\end{array}$} & \multirow{2}{*}{$\begin{array}{c}\text { Mean age } \\
\text { (years) }\end{array}$} & \multirow{2}{*}{$\begin{array}{l}\text { Person-hours } \\
\text { worked }\end{array}$} & \multirow{2}{*}{$\begin{array}{l}\text { Potential affordable } \\
\text { workdays of all } \\
\text { employees }\end{array}$} & \multirow{2}{*}{$\begin{array}{l}\text { Total } \\
\text { disabled } \\
\text { days }\end{array}$} & \multicolumn{2}{|c|}{ Potential workdays lost } \\
\hline & & & & & & ANSI & Taiwan \\
\hline 1985 & 9614 & 31.69 & 21318818 & 96022149 & 15501 & 26791 & 31244 \\
\hline 1986 & 9667 & 32.52 & 22318952 & 94131470 & 5961 & 10272 & 13833 \\
\hline 1987 & 9807 & 33.33 & 23345482 & 93109980 & 36751 & 60332 & 61982 \\
\hline 1988 & 9879 & 34.21 & 22713801 & 91184916 & 8884 & 14436 & 15133 \\
\hline 1989 & 9864 & 35.16 & 22578041 & 88249735 & 14324 & 16135 & 16332 \\
\hline 1990 & 9813 & 36.08 & 22791051 & 85090381 & 13608 & 14148 & 14329 \\
\hline 1991 & 9748 & 37.04 & 22800047 & 81710449 & 8226 & 12681 & 13367 \\
\hline
\end{tabular}

number of employees, mean age, person-hours worked, potential affordable workdays of all employees, and the various kinds of estimation of workdays lost. The number of employees and the person-hours worked do not fluctuate much in these years, but the mean age of all employees increases and is reflected in the declining number of total potential affordable workdays. The magnitude of change during 1985-1991 for the total number of disabling days charged by ANSI's schedule seems to be larger when compared with those of the potential workdays lost.

Table 5 shows the figures of these indices in two aspects, the frequency and severity of injury. The mortality rate was greatest in 1987, which had five cases of fatality. The disabling frequency rate peaked in 1989 and then declined. However, either $\mathrm{CIR}_{20-64}$ or $\mathrm{CIR}_{\mathrm{DOE} 0-24}$ had its highest value in 1988 rather than in 1989. As for the severity-related indices, the figures for all indices 
Table 5. Frequencies and severities of occupational injuries that occurred in a steel making company from 1985 through 1991. $\left(\mathrm{CIR}_{20-64}=\right.$ cumulative injury rate between 20 and 64 years of age, CIR $\mathrm{Dog}-24=$ cumulative injury rate on duration of employment between 0 and 24 years, PPWDL = proportion of potential work days lost, ANSI = American National Standards Institute)

\begin{tabular}{|c|c|c|c|c|c|c|c|}
\hline & & & & Years & & & \\
\hline & 1985 & 1986 & 1987 & 1988 & 1989 & 1990 & 1991 \\
\hline \multicolumn{8}{|l|}{ Frequency of injury } \\
\hline $\begin{array}{l}\text { Mortality rate }\left(10^{-3}\right) \\
\text { Frequency rate } \\
\text { ClR }_{20-64} \\
\text { CIR }_{\text {DOE0-24 }}\end{array}$ & $\begin{array}{l}0.10 \\
3.38 \\
0.32 \\
0.10\end{array}$ & $\begin{array}{l}0.00 \\
3.63 \\
0.47 \\
0.12\end{array}$ & $\begin{array}{l}0.51 \\
4.37 \\
0.32 \\
0.15\end{array}$ & $\begin{array}{l}0.10 \\
4.80 \\
0.59 \\
0.49\end{array}$ & $\begin{array}{l}0.10 \\
5.05 \\
0.44 \\
0.21\end{array}$ & $\begin{array}{l}0.20 \\
3.51 \\
0.43 \\
0.16\end{array}$ & $\begin{array}{l}0.10 \\
2.94 \\
0.30 \\
0.24\end{array}$ \\
\hline \multicolumn{8}{|l|}{ Severity of injury } \\
\hline $\begin{array}{l}\text { Severity rate } \\
\text { Severity index (ANSI) } \\
\text { Severity index (Taiwan) } \\
\text { PPWDL (10-6, ANSI) } \\
\text { PPWDL }\left(10^{-6} \text {, Taiwan) }\right.\end{array}$ & $\begin{array}{r}727 \\
1257 \\
1466 \\
279 \\
325\end{array}$ & $\begin{array}{l}267 \\
460 \\
620 \\
109 \\
147\end{array}$ & $\begin{array}{r}1574 \\
2584 \\
2655 \\
648 \\
666\end{array}$ & $\begin{array}{l}391 \\
636 \\
666 \\
158 \\
166\end{array}$ & $\begin{array}{l}634 \\
715 \\
723 \\
183 \\
185\end{array}$ & $\begin{array}{l}597 \\
621 \\
629 \\
166 \\
168\end{array}$ & $\begin{array}{l}361 \\
556 \\
586 \\
155 \\
164\end{array}$ \\
\hline
\end{tabular}

Table 6. Estimation of potential salary lost from three different outcomes of occupational injuries from 1985 through 1991 that occurred in a company with various discount rates (r). (Unit: USD 100 000)

\begin{tabular}{|c|c|c|c|c|c|c|c|}
\hline & \multicolumn{7}{|c|}{ Year } \\
\hline & 1985 & 1986 & 1987 & 1988 & 1989 & 1990 & 1991 \\
\hline \multicolumn{8}{|l|}{ Death } \\
\hline $\begin{array}{l}r=0.04 \\
r=0.06 \\
r=0.08 \\
r=0.10\end{array}$ & $\begin{array}{r}12.48 \\
8.71 \\
6.33 \\
4.78\end{array}$ & $\begin{array}{l}0.00 \\
0.00 \\
0.00 \\
0.00\end{array}$ & $\begin{array}{l}61.94 \\
43.31 \\
31.66 \\
24.10\end{array}$ & $\begin{array}{r}13.69 \\
9.38 \\
6.73 \\
5.04\end{array}$ & $\begin{array}{l}4.34 \\
3.72 \\
3.22 \\
2.82\end{array}$ & $\begin{array}{r}13.32 \\
10.49 \\
8.45 \\
6.97\end{array}$ & $\begin{array}{r}13.06 \\
9.02 \\
6.51 \\
4.89\end{array}$ \\
\hline \multicolumn{8}{|l|}{ Permanent injury } \\
\hline $\begin{array}{l}r=0.04 \\
r=0.06 \\
r=0.08 \\
r=0.10\end{array}$ & $\begin{array}{r}18.91 \\
14.07 \\
10.97 \\
8.93\end{array}$ & $\begin{array}{r}10.56 \\
7.59 \\
5.79 \\
4.65\end{array}$ & $\begin{array}{l}8.49 \\
6.72 \\
5.50 \\
4.64\end{array}$ & $\begin{array}{l}1.89 \\
1.50 \\
1.24 \\
1.06\end{array}$ & $\begin{array}{r}11.21 \\
8.31 \\
6.40 \\
5.10\end{array}$ & $\begin{array}{l}0.17 \\
0.14 \\
0.12 \\
0.10\end{array}$ & $\begin{array}{l}0.62 \\
0.52 \\
0.45 \\
0.40\end{array}$ \\
\hline Temporary injury & 0.82 & 1.38 & 1.56 & 1.32 & 1.51 & 0.98 & 1.26 \\
\hline \multicolumn{8}{|l|}{ Total } \\
\hline $\begin{array}{l}r=0.04 \\
r=0.06 \\
r=0.08 \\
r=0.10\end{array}$ & $\begin{array}{l}32.21 \\
23.60 \\
18.12 \\
14.53\end{array}$ & $\begin{array}{r}11.94 \\
8.97 \\
7.17 \\
6.03\end{array}$ & $\begin{array}{l}71.99 \\
51.59 \\
38.72 \\
30.30\end{array}$ & $\begin{array}{r}16.90 \\
12.20 \\
9.29 \\
7.42\end{array}$ & $\begin{array}{r}17.06 \\
13.54 \\
11.13 \\
9.43\end{array}$ & $\begin{array}{r}14.47 \\
11.61 \\
9.55 \\
8.05\end{array}$ & $\begin{array}{r}14.94 \\
10.80 \\
8.22 \\
6.55\end{array}$ \\
\hline
\end{tabular}

show similar trends except for the last three years. For 1985 and 1989 , the results of the disabling severity rate are less exaggerated than those from the severity index and the proportion of potential workdays lost. In 1989 there was one case of fatality, seven cases of permanent disability, and 106 cases of temporary dysfunction, while in 1985 there was one case of fatality, 11 cases of permanent disability, and 60 cases of temporary dysfunction (table 3). But the severity rate in 1985 (727 disabled days per million person-hours worked) was only 1.1 -fold higher than that in 1989 (634 disabled days per one million person-hours worked) (table 5). With the severity index, the result of 1985 is 1.7 -fold higher than that of 1989 by ANSI's schedule (1257 versus 715 potential workdays lost per million person-hours worked); and about twofold higher if calculated and compared with Taiwan's schedule (1466 versus 723). With the proportion of potential workdays lost, we can obtain a smaller magnitude of the difference for these two years if they are compared with those of the severity index (ie, 1.52-fold for the proportion of potential workdays lost for ANSI and 1.75fold for the proportion of potential workdays lost for Taiwan). The figures fluctuate more smoothly after 1988 for both ANSI's and Taiwan's methods. It adjusts the various age distributions of employees in each year, and we can tell that there was a small improvement in occupational safety from 1990 to $1991,166\left(10^{-6}\right)$ to $155\left(10^{-6}\right)$ by ANSI's schedule and from $168\left(10^{-6}\right)$ to $164\left(10^{-6}\right)$ by Taiwan's schedule, which is not so large as that shown for the severity rates (597 to 361 disabled days per million person-hours worked).

Table 6 exhibits the potential salary lost in monetary value. On the assumption that any age and either gender have the same income in our example, we used USD 23000 as the average annual income for the calculation of three equations. With four different discount rates, we obtained four pairs of figures for death and permanent disability. Because the potential salary lost due to temporary dysfunction only counts the actual loss of the year in which the injury occurred, it does not change with differ- 
ent discount rates. With any discount rate, the potential salary lost from death remains the major part of the total potential salary lost, except in 1985 and 1989, which had more than seven cases of permanent disability. When the discount rate becomes larger, the figures for permanent disability come close to those of temporary dysfunction, or are even less than them, as shown for 1988. The potential salary lost due to occupational injuries in 1991 is about one million American dollars when the discount rate is $6 \%$.

\section{Discussion}

Both the disabling frequency and severity rates have been used to quantify and monitor the status of occupational injuries in firms since 1967 (5). However, these two indicators are not without drawbacks. The disabling frequency rate is actually a crude rate, which needs to be further standardized in order for comparison between different companies or different years. Moreover, it cannot be directly interpreted as a personal lifetime risk of acquiring occupational injuries in a particular company. As for the disabling severity rate, the measurement of the total disabling days is relatively arbitrary and fixed for permanent disability and death. It is not based upon a worker's potential work capability lost or remained, but changes with the rigidly weighted disabled days for injury to different parts of the body.

As an alternative to the disabled frequency rate, we propose the $\mathrm{CIR}_{20-64}$ and $\mathrm{CIR}_{\mathrm{DOE} 0-24}$ to quantify the frequencies of occupational injuries. These two indicators not only allow for inherent adjustments for uneven age distribution or duration of employment, but also serve as indicators assessing a worker's cumulative risk of acquiring occupational injuries in a specific company. In other words, the $\mathrm{CIR}_{20-64}$ represents an employee's lifetime cumulative risk of acquiring an occupational injury, while the $\mathrm{CIR}_{\mathrm{DOE} 0-24}$ indicates the average risk of acquiring an occupational injury after working for 25 years in the company if the worker has not left for any other reasons. For instance, if an employee works in the firm of our example from 20 years of age to retirement, the average risk of acquiring an occupational injury in the work environment of 1991 is $30 \%$ (table 5). Similarly, the risk of acquiring an occupational injury for an employee working for 25 years is $24 \%$ for the same environment of 1991. However, since the $\mathrm{CIR}_{20-64}$ uniformly weights each age stratum, it will be affected by any age stratum with a small number of population at risk. For example, a disabling injury occurred for one out of every 14 workers in the age stratum of $60-64$ in the year of 1986 (not shown in the tables). This occurrence heavily influences the figure of $\mathrm{CIR}_{20-64}$ of 1986 and makes it the second highest during 1985-1991. The bias generated from a small fraction of the population at risk in a particular stratum might be mild when we apply this indicator to fit the data from the national level. However, we recommend that users look with caution at the CIR values, including $\mathrm{CIR}_{20-64}$ and $\mathrm{CIR}_{\mathrm{DOE} 0-24}$. A duration of employment of 0 and 24 years was used because a worker is eligible for retirement if he or she has worked for 25 years in the same firm according to the labor regulations in Taiwan. This upper limit of employment duration can be different for countries with different criteria for retirement. As long as the time period specified for either age or duration of employment is the same, they can be directly compared.

The concept of potential workdays lost involves the actual estimation of the potential workdays a worker would lose if he or she died or sustained disabilities due to occupational injuries. The total potential workdays lost can be directly interpreted as a quantitative loss of human resources to society and converted into a monetary value. The severity index introduces the total potential workdays lost to serve as the numerator. Since the denominator of the severity index is still the same as the severity rate (ie, per million person-hours worked) the severity index still has potential bias against the impact of the death or permanent disability of young workers, who generally have longer potential work lives than those of the aged. The proportion of potential workdays lost can amend such flaws by incorporating the age distribution into the calculation. It replaces the per million person-hours worked with the total potential affordable workdays for the denominator of the severity index. The calculation of the proportion of potential workdays lost assumes that all employees will work in the firm until retirement age and will not leave for any other reason before retirement. This should not distort the meaning, because the total potential workdays lost of injured employees comes from all the employees who contribute to the total potential affordable workdays. Since most permanent disabilities due to occupational injuries are mild to moderate [in our example, only two out of 38 belong to the moderate injury class (grade 4-6), see table 3], the assumption is not violated in most cases. Workers with severe disabilities that affect their own survival generally have a low residual work capability, and thus the error due to the poor survival of disabled workers may be trivial. Moreover, before one's retirement, there might be some interactive effect of occupational injuries with other health-related events affecting work capability, such as diabetes mellitus, cardiovascular diseases, cancer, infectious diseases or the like, in his or her work career. Since working populations are generally healthier than those unemployed $(14-16)$ and the effect would similarly affect all work forces, we assume that the magnitude of interaction may not be too large and will prob- 
ably not bias the estimation of our model to a significant extent. However, if we want to extend our model to other occupational and nonoccupational diseases, both the survival time of the specific health-related event and the residual work capability should be taken into consideration simultaneously. In this case, the competing risk of dying from other causes can also be taken care of (8), and we can extend the model to quantify the potential workdays lost of either acute or chronic health events and to estimate their impact on society.

To determine an employee's work capability is a difficult task and probably cannot be completed by a single figure or dimension. Since we are lacking such data at present, we simply defined the loss of work capability by comparing it with that before the injury as a percentage, adopting the schedules of Taiwan and ANSI as examples, shown in tables 1 and 2 . However, the real figure may be different because these quick schedules were not originally made for estimating a worker's loss of work capability. Thus we suggest conducting surveys of workers who have suffered from various degrees of severity of occupational injuries to determine the percentage of change in work capability after injury and to validate further the figures of the 15 grades in table 1 or those of ANSI's schedule in table 2. Although rare, it is possible that an injured employee with a relatively mild permanent disability may return to work with an improved work capability than that prior to the injury, as in figure 4. Such a gain or improvement in work capability generally cannot be attributed directly to the injury because the victim usually goes through much pain and psychological trauma after one injury. The condition is even worse for any injury resulting in permanent disability of a more serious nature. Therefore, we suggest treating such cases as outliers until actual survey data are obtained to refute or to verify our proposal. Since these cases may be relatively rare, they will probably not affect our overall estimation significantly.

Among different dimensions for estimating the cost of occupational injuries, foregone earnings of affected workers remain a major part (17). Using the concept of potential workdays lost, we have also proposed a model to calculate the potential salary lost. Determinants of such an estimation, (eg, the growth of labor productivity,

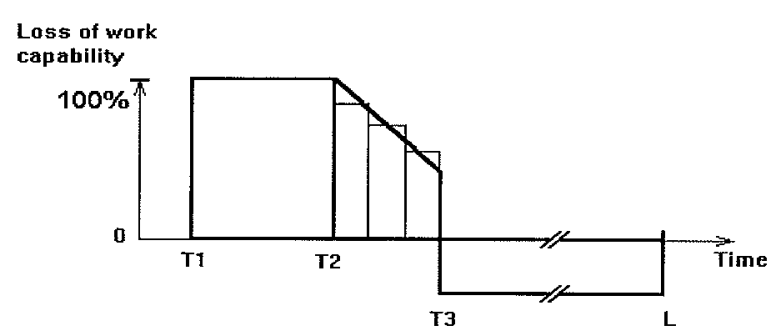

Figure 4. Possible condition for gaining surplus work capability due to permanent disability from the occupational injury of an employee. real interest rate and annual individual income) are adjusted in our model, which offers a straight way of estimating the severity of occupational injuries in monetary value. When the estimation extends to the national level, we can use the average income instead. Nevertheless, adjustment for some key factors influencing a worker's income, such as industry, occupation, education, and the like can also be further taken into account and factored into the equations (17). Although this approach, based on the method of human capital, may not be so convincing as the estimation from the method of "willingness to pay" (18), it can be considered as its lower limit (13) and still provides us with a direct and quick tool for counting the potential monetary cost for occupational injuries.

The $\mathrm{CIR}_{20-64}, \mathrm{CIR}_{\mathrm{DOE} 0-24}$, severity index, proportion of potential workdays lost, and total potential salary lost are expected to serve as quantification and summarization tools towards describing the issue of occupational injuries, in addition to helping the established disabling frequency and severity rates. We anticipate that these indicators can be applied to the policy-making process of occupational safety and health. Furthermore, the applications of the concept of potential workdays lost can be similarly extended to other occupational and nonoccupational diseases and used to calculate the costs of human resources for both policy-decision analysis and evaluation in issues of public health.

\section{Acknowledgments}

The authors are indebted to Dr Wen-Chung Lee and an anonymous referee for their valuable comments on $\mathrm{cu}$ mulative injury rate. This research has been supported by center grant no DOH82-HP-2101 from the Department of Health, Executive Yuan, Republic of China.

\section{References}

1. Pappas JL, Hirschey M. Managerial economics. 6th edition. Orlando (FL): Dryden, 1990:3-22.

2. Rice DP, MacKenzie EJ, and associates. Cost of injury in the United States: a report to congress. San Francisco (CA): Institute for Health \& Aging, University of California and Injury Prevention Center, The John Hopkins University, 1989:3785.

3. Harlan LC, Harlan WR, Parsons PE. The economic impact of injuries: a major source of medical costs. Am J Public Health 1990;80:453-9.

4. Grimaldi JV, Simonds RH. Safety management, 3rd edition. Homewood (IL): Irwin, 1975:14-24.

5. American National Standards Institute. Method of recording and measuring work injury experience. New York $(\mathrm{NY})$ : American National Standards Institute, 1967. American National Standard Z16.1. 
6. Gojer JE, Johanson U. Human resource costing and accounting. Stockholm: Joint Industrial Safety Council, 1991:17-33.

7. Gardner JW, Sanborn JS. Years of potential life lost (YPLL) what does it measure? Epidemiology 1990;1:322-9.

8. Hakulinen T, Teppo L. The increase in working years due to elimination of cancer as a cause of death. Int $J$ Cancer 1976;17: 429-35.

9. Wang JD. Principles of epidemiological research. Taipei (Taiwan): Publication Committee of the National Taiwan University College of Medicine, 1990:19-113.

10. Miettinen OS. Theoretical epidemiology. New York (NY): Wiley, 1985:246-9.

11. Rothman KJ. Modern epidemiology. Boston/Toronto: Little Brown, 1986:23-4.

12. Bureau of Labor Insurance For Taiwan-Fukien Area ROC. Regulation of labor insurance. Taipei: Bureau of Labor Insurance For Taiwan-Fukien Area ROC, 1992:92-130.

13. Kenkel D. Cost of illness approach. In: Tolley G, Kenkel D,
Fabian R, editors. Valuing health for policy. Chicago (IL): University of Chicago Press, 1994:42-71.

14. McMichael JA. Standardized mortality ratios and the "healthy worker effect": scratching beneath the surface. J Occup Med 1976;18(3):165-8

15. Fox AJ, Collier PF. Low mortality rates in industrial cohort studies due to selection for work and survival in the industry. Br J Prev Soc Med 1976;30:225-30.

16. Choi BCK. Definitions, sources, magnitude, effect modifiers, and strategies of reduction of the healthy worker effect. J Occup Med 1992;34:979-88.

17. Drummond MF, Stoddart GL, Torrance GW. Methods for the economic evaluation of health care programmes. Oxford: Oxford University Press, 1987:45-53.

18. Landefeld JS, Seskin EP. The economic value of life: linking theory to practice. Am J Public Health 1982;72:555-66.

Received for publication: 23 November 1993 